\title{
Management of pneumothorax in hemodynamically stable preterm infants using high frequency oscillatory ventilation: report of five cases
}

\author{
Claudia Aurilia, Cinzia Ricci, Milena Tana, Chiara Tirone, Alessandra Lio, Alessandro Gambacorta, \\ Angela Paladini and Giovanni Vento*
}

\begin{abstract}
Background: Despite an increased use of non-invasive ventilatory strategies and gentle ventilation, pneumothorax remains a common complication in preterm infants. The ventilator management of infants with air leaks remains challenging in terms of both prevention and treatment. Recently the safety and efficacy of expectant management avoiding chest tube drainage to treat large air leak in preterm infants hemodynamically stable has been reported.

Case presentation: In the present study, we report five cases of preterm infants with birth weight $\leq 1250 \mathrm{~g}$ affected by respiratory distress syndrome and treated with nasal continuous positive airway pressure as first intention. They were intubated for worsening of respiratory distress with increasing oxygen requirement and concomitant increase of respiratory rate and $\mathrm{P}_{\mathrm{CO} 2}$ values due to occurrence of pneumothorax, and they were successfully treated using high-frequency oscillatory ventilation without chest tube insertion.

Conclusion: In our experience high-frequency oscillatory ventilation provided a conservative management of a significant pneumothorax in preterm newborns hemodynamically stable and requiring mechanical ventilation. This approach allowed us to avoid the increasing of air leak and the insertion of chest tube drainage and all the subsequent associated risks.
\end{abstract}

Keywords: Pneumothorax, Preterm infants, HFOV, Chest drainage

\section{Background}

Pneumothorax is a relatively common complication in newborns infants $(6-10 \%$ in very low birth weight preterm infants and around $1 \%$ in term infants [1]), especially when receiving invasive mechanical ventilation, but also during non-invasive ventilatory support such as continuous positive airways pressure (CPAP) [2]. A 40\% increase of $\mathrm{FiO}_{2}$ during the first $24 \mathrm{~h}$ of CPAP has been suggested as a useful marker to identify the infants at high risk of developing a pneumothorax [3]. Recently successful management strategies have been reported of symptomatic

\footnotetext{
* Correspondence: giovanni.vento@unicatt.it

Division of Neonatology, Department for the protection of women's health and the nascent life, child and adolescent, Fondazione Policlinico

Universitario A. Gemelli-Università Cattolica del Sacro Cuore, Largo A. Gemelli 8, 00168 Rome, Italy
}

pneumothorax diagnosed in preterm infants receiving assisted ventilation, which avoided chest tube drainage and resulted in reduction of important side effects $[4,5]$. In this case series, we reported our experience of using highfrequency oscillatory ventilation (HFOV) as a first-line treatment of pneumothorax in preterm infants with respiratory distress syndrome.

\section{Cases presentation}

We report the experience of five neonates (4 males and 1 female), with mean \pm SD birth weight of $1211 \pm 40 \mathrm{~g}$ and mean \pm SD gestational age of $30 \pm 2$ weeks. All infants were delivered by caesarean section due to preeclampsia (one case), gestational hepatosis and preeclampsia (one case), preterm labor (one case), growth restriction (one case) and ascites of the second twin (one 
case); three of them were twin-birth. Premature rupture of membranes did not occur in any of the cases. All the mothers received at least one dose of betamethasone. Soon after birth, all the infants developed respiratory distress (Silverman score 3-4) and were placed on a ventilator nasal CPAP system with a pressure level of 4$6 \mathrm{cmH}_{2} \mathrm{O}$ and a $\mathrm{FiO}_{2}$ of $0.25-0.30$ for a diagnosis of respiratory distress syndrome based also on the typical chest X-ray. CPAP failure criteria $\left(\mathrm{FiO}_{2} \geq 0.40\right)$ was reached in two cases (patient 3 and 5), and surfactant was administered $(200 \mathrm{mg} / \mathrm{kg}$ of poractant alfa, Chiesi Farmaceutici, Italy) with the INtubation-SURfactantExtubation (INSURE) approach respectively at $9 \mathrm{~h}$ and $6 \mathrm{~h}$ of life.

On median [range] postnatal day 3 [2-4] respiratory distress (quantified by means of Silverman score) worsened, with a concomitant increase of respiratory rate, of capillary $\mathrm{P}_{\mathrm{CO} 2}$ values and of $\mathrm{FiO}_{2}$ to obtain $\mathrm{SpO}_{2}$ values 90-95\% (Table 1). Chest X-rays showed the presence of pneumothorax on the right side in two patients and on the left side in the other three ones. Heart rate and blood pressure remained within normal range for the gestational age. All 5 neonates were intubated and mechanically ventilated using HFOV delivered by a BabyLog 8000 plus ventilator (Dräger, Lubeck, Germany) in the first 4 cases and by a BabyLog VN500 (Dräger, Lubeck, Germany) in the 5th case (Table 1). Ventilation was started with a median [range] mean airways pressure (MAP) of 8 [8-9] $\mathrm{cmH}_{2} \mathrm{O}$, amplitude of $100 \%$ in the first 4 cases and $\Delta \mathrm{P}$ of $15 \mathrm{~cm} \mathrm{H}_{2} \mathrm{O}$ in the last case ventilated with Baby-log VN500, frequency of $10 \mathrm{~Hz}$. The oscillation amplitude with the BabyLog 8000 plus is adjustable as a percentage from 0 to $100 \%$, where $100 \%$ means the highest possible amplitude under the given circumstances of MAP and frequency settings as well as the characteristics of the respiratory system. In the first 4 cases receiving HFOV by BabyLog 8000 plus, amplitude was gradually increased up to $100 \%$ until the infant's

Table 1 Patients characteristics, pneumothorax details, respiratory status prior to intubation and starting ventilatory parameters

\begin{tabular}{|c|c|c|c|c|c|}
\hline $\bar{C}$ & Patient 1 & Patient 2 & Patient 3 & Patient 4 & Patient 5 \\
\hline Gestational Age (weeks) & $31^{+6}$ & $30^{+2}$ & $27^{+5}$ & $33^{+2}$ & $28^{+5}$ \\
\hline Sex & Male & Male & Female & Male & Male \\
\hline Birth Weight (g) & 1240 & 1215 & 1205 & 1250 & 1145 \\
\hline Delivery & Caesarean section & Caesarean section & Caesarean section & Caesarean section & Caesarean section \\
\hline Respiratory Diagnosis & $\begin{array}{l}\text { Respiratory Distress } \\
\text { Syndrome }\end{array}$ & $\begin{array}{l}\text { Respiratory Distress } \\
\text { Syndrome }\end{array}$ & $\begin{array}{l}\text { Respiratory Distress } \\
\text { Syndrome; Candida } \\
\text { spp. pneumonia }\end{array}$ & $\begin{array}{l}\text { Respiratory Distress } \\
\text { Syndrome; Group B } \\
\text { Streptococcus pneumonia }\end{array}$ & $\begin{array}{l}\text { Respiratory Distress } \\
\text { Syndrome }\end{array}$ \\
\hline Time of Surfactant & No & $\begin{array}{l}\text { At } 36 \mathrm{~h} \text { of life, after } \\
\text { intubation }\end{array}$ & $\begin{array}{l}\text { INSURE at } 9 \mathrm{~h} \text { of life; } \\
2 \text { nd dose at } 50 \mathrm{~h} \text { of } \\
\text { life, after intubation }\end{array}$ & No & $\begin{array}{l}\text { INSURE at } 6 \mathrm{~h} \text { of } \\
\text { life }\end{array}$ \\
\hline $\begin{array}{l}\text { Pneumothorax diagnosis } \\
\text { (day of life) }\end{array}$ & 3 & 2 & 3 & 4 & 3 \\
\hline Site of the pneumothorax & Left & Left & Right & Right & Left \\
\hline $\begin{array}{l}\text { Pneumothorax resolution } \\
\text { (day of life) }\end{array}$ & 5 & 4 & 7 & 6 & 6 \\
\hline Extubation (day of life) & 5 & 4 & 8 & 6 & 6 \\
\hline CPAP level $\left(\mathrm{cmH}_{2} \mathrm{O}\right)$ & 4 & 4 & 6 & 4 & 4 \\
\hline Maximum $\mathrm{FiO}_{2}$ & 0.50 & 0.70 & 0.60 & 0.50 & 0.50 \\
\hline Maximum Silverman score & 6 & 6 & 5 & 7 & 4 \\
\hline $\begin{array}{l}\text { Spontaneous respiratory rate } \\
\text { (breaths per minute) }\end{array}$ & 95 & 110 & 75 & 110 & 90 \\
\hline pH, capillary blood & 7.22 & 7.22 & 7.29 & 7.27 & 7.29 \\
\hline $\mathrm{P}_{\mathrm{CO} 2}(\mathrm{mmHg})$, capillary blood & 58 & 64 & 59 & 64 & 60 \\
\hline MAP $\left(\mathrm{cmH}_{2} \mathrm{O}\right)$ & 8 & 9 & 8 & 8 & 8 \\
\hline Frequency $(\mathrm{Hz})$ & 10 & 10 & 10 & 10 & 10 \\
\hline $\mathrm{FiO}_{2}$ & 0.50 & 0.50 & 0.50 & 0.50 & 0.50 \\
\hline Amplitude, $\left(\%\right.$ or $\left.\mathrm{cmH}_{2} \mathrm{O}^{\mathrm{a}}\right)$ & 100 & 100 & 100 & 100 & $15^{\mathrm{a}}$ \\
\hline
\end{tabular}

MAP: mean airways pressure; CPAP: continuous positive airway pressure; INSURE: INtubation-SURfactant-Extubation

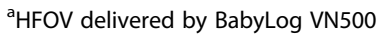


chest was seen to be "visibly vibrating", providing the MAP as low as possible for the presence of air leak. All the newborns received Remifentanil by continuous intravenous infusion at a dose of $0.075 \mu \mathrm{g} / \mathrm{kg} / \mathrm{min}$ to provide analgesia and sedation during HFOV [6]. Despite the start of mechanical ventilation, the $\mathrm{FiO}_{2}$ requirement remained quite high $(0.50-0.60)$ in two cases (patients 2 and 3) and these neonates received 1 dose of surfactant (Table 1). In two patients, a diagnosis of pneumonia was made afterwards, based on the results of bronchoalveolar lavage fluid culture positive for Candida spp. (patient3) and for Group B Streptococcus (patient 4) (Table 1). In all the five cases, the infants' oxygen requirement and ventilatory support gradually decreased during the subsequent days. Chest X-rays showed a progressive and complete resolution of the pneumothorax within 48-96 h (Fig. 1). All the infants were successfully extubated with a median [range] MAP of 6 [5.5-6] $\mathrm{cmH}_{2} \mathrm{O}$, amplitude of 100 [25-100] \% in the first 4 cases and $\Delta \mathrm{P}$ of $15 \mathrm{~cm} \mathrm{H}_{2} \mathrm{O}$ in the last case, frequency of 8 [7-10] $\mathrm{Hz}$ and $\mathrm{FiO}_{2}$ of 0.23 [0.21-0.25]. All infants survived with normal head ultrasounds and without bronchopulmonary dysplasia, defined as oxygen requirements or need of ventilatory support at 36 weeks of post menstrual age.

\section{Discussion and conclusion}

Despite an increased use of non-invasive ventilator strategies and gentle ventilation, pneumothorax remains a common complication in preterm infants. The ventilator management of infants with air leaks remains challenging in terms of both prevention and treatment. Several reports have described the successful application of high frequency ventilation (HFV) in adults with airway disruption or bronchopleural fistulae and in newborns with persistent air leaks through pneumothorax [7, 8]. Gonzalez et al. showed a decreased gas flow through chest tube insertion in neonates affected by pneumothorax receiving high-frequency jet ventilation with respect to those who received conventional ventilation [7]. Various forms of HFV have been used to treat infants with pulmonary air leak and the superiority of this type of ventilation over conventional ventilation has been shown [9]. It is not clear how HFV improves the healing of air leaks, but a ventilator strategy incorporating short inspiratory time and high respiratory rates is often effective in decreasing the
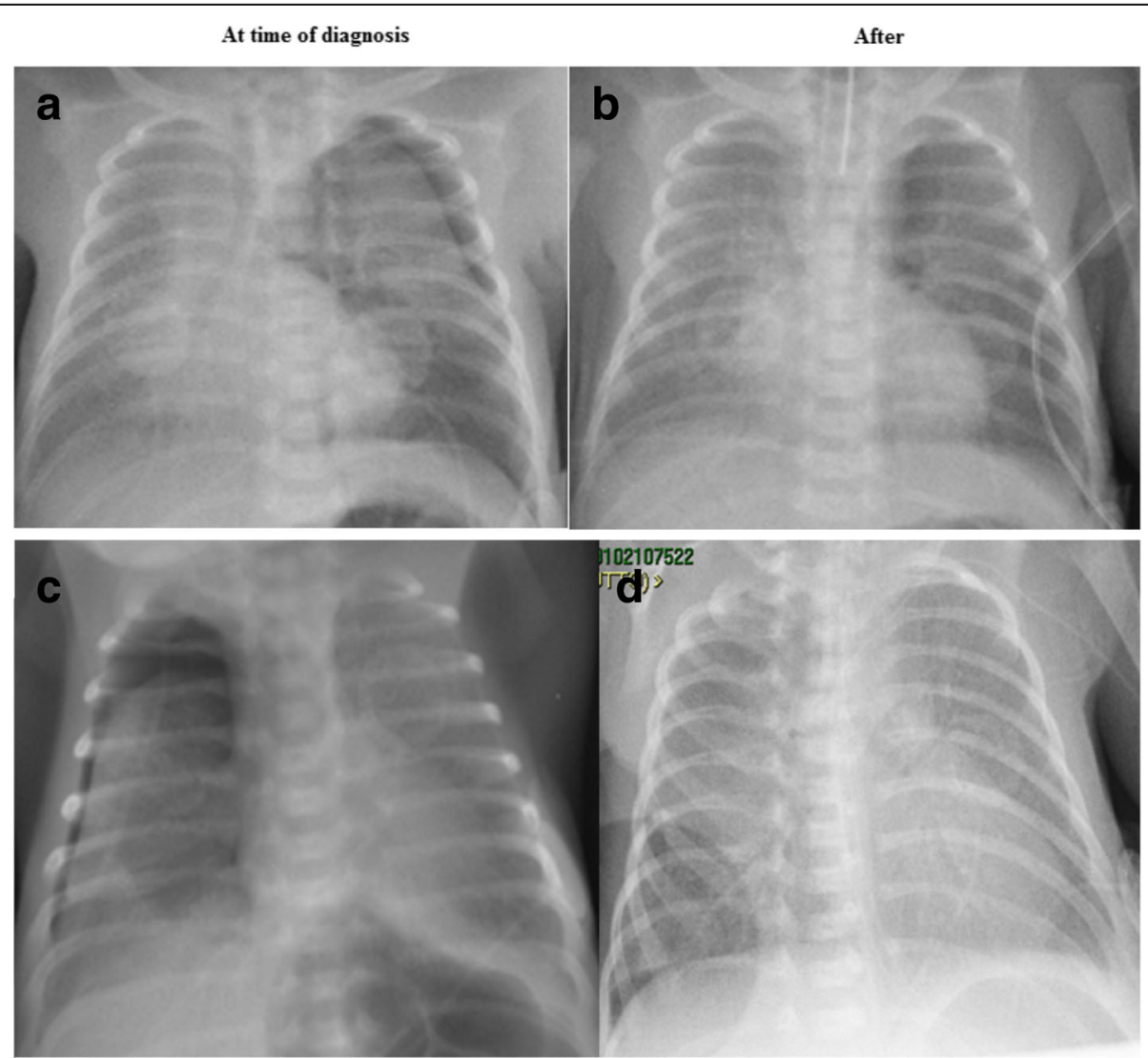

Fig. 1 Chest X Rays of patient 1 and patient 4. Legend: patient 1: a: left side pneumothorax. b: resolution of pneumothorax $48 \mathrm{~h}$ later; patient 4 : c: right side pneumothorax. d: resolution of pneumothorax $48 \mathrm{~h}$ later 
magnitude of the leak $[7,8,10]$. It is most likely that the absence of high-peak inspiratory pressures, the very short absolute inspiratory time and small tidal volume applied at higher frequencies may result in a rapid decrease of air leak, as showed by Ellsbury et al. in an animal model of pneumothorax [11]. For these reasons, in the presence of gross air leak (e.g. pneumothorax), strategy should prioritise low tidal volume ventilation, more easily obtained during HFOV (1.5-2.5 ml/kg) respect to conventional mechanical ventilation (4-6 ml $/ \mathrm{kg}$ ). Management of MAP is also a critical tool and aggressive lung volume recruitment has to be avoided. MAP should be reduced where possible then maintained at a pressure sufficient to stent small airways open to avoid progression of the air leak and to guarantee sufficient oxygenation without high $\mathrm{FiO}_{2}$ requirements [12].

Recently Kitsommart et al. [4] reported 4 cases of preterm infants who developed large pneumothoraces, two of whom remaining on nasal CPAP after the diagnosis. In our experience, all the neonates developed worsening respiratory severity in terms of increasing of respiratory rate, Silverman score, $\mathrm{FiO}_{2}$ requirement and $\mathrm{PCO}_{2}$ values, making intubation mandatory. HFOV was used as first choice of treatment (not as rescue, without a chest tube) and the strategy was found successful.

Our experience reported data on the successful use of HFOV to provide conservative management of a significant pneumothorax in preterm newborns. In our opinion this approach could be used in preterm newborns developing pneumothorax while they are on nasal CPAP, remaining hemodynamically stable without clinical signs of tension pneumothorax (i.e. cyanosis, significant decline of arterial blood pressure, heart rate, respiratory rate, and $\mathrm{SpO}_{2}$ ) [13] but requiring mechanical ventilation for acute worsening of the respiratory status. The suggested starting ventilator parameters in course of HFOV for pneumothorax treatment are: MAP 8-9 cm $\mathrm{H}_{2} \mathrm{O}, \mathrm{FiO}_{2}$ to achieve $\mathrm{SpO}_{2}$ 90-95\%, Respiratory Rate: $10 \mathrm{~Hz}, \mathrm{I}: \mathrm{E}=1: 2, \Delta \mathrm{P}: 15 \mathrm{~cm} \mathrm{H}_{2} \mathrm{O}$, eventually increased chest to be «visibly vibrating ». This approach allowed us to avoid the increasing of air leak and the insertion of chest tube drainage and all the subsequent associated risks. However, there is no control population to which these 5 cases were compared, i.e. the pneumothorax may have resolved on their own regardless of ventilator modality. Nevertheless, considering both the reassuring outcomes observed in our babies and the risks of thoracic organ injury related to chest tube insertion because of supple chest wall, close proximity of vital structures and frail lung tissue of preterm babies, our experience could provide a starting point for novel hypothesis-testing clinical research (i.e. by comparing the conservative management of pneumothorax by HFOV or conventional mechanical ventilation in preterm infants).
Chest tube insertion for definitive drainage of a tension pneumothorax should be provided when this complication not only produces worsening of respiratory status (increase of respiratory rate, Silverman score, $\mathrm{FiO}_{2}$ requirement and $\mathrm{PCO}_{2}$ values), but also a hemodynamic instability of the patients (e.g. bradycardia, hypotension).

\begin{abstract}
Abbreviations
CPAP: Continuous positive airways pressure; HFOV: High-frequency oscillatory ventilation; HFV: High frequency ventilation; MAP: Mean airways pressure
\end{abstract}

\section{Acknowledgments}

We thank the families of patients for their understanding cooperation and the nursing staff for its invaluable support.

\section{Funding}

This research received no specific grant from any funding agency in the public, commercial or not-for-profit sectors.

\section{Availability of data and materials}

The datasets used and/or analysed during the current study are available from the corresponding author on reasonable request.

\section{Authors' contributions}

CA carried out the data collection and the initial analyses and reviewed the manuscript. CR carried out the data collection and the literature search, prepared and reviewed the manuscript. MT carried out the data collection and drafted the initial manuscript. CT carried out the data collection and the initial analyses, reviewed and revised the manuscript. AL carried out the data collection, the literature search, reviewed and revised the manuscript. AG and AP carried out the data collection, the literature search, reviewed and revised the manuscript. GV conceptualized and designed the study and critically reviewed the manuscript. All authors read and approved the final manuscript.

\section{Ethics approval and consent to participate}

The study was approved by the Ethics Committee of the Policlinico Universitario A. Gemelli-Università Cattolica del S. Cuore, Rome.

\section{Consent for publication}

Written informed consent was obtained from the parents of the patients for publication of this cases report and any accompanying images. A copy of the written consent is available for review by the Editor of this journal.

\section{Competing interests}

The authors declare that they have no competing interests.

\section{Publisher's Note}

Springer Nature remains neutral with regard to jurisdictional claims in published maps and institutional affiliations.

Received: 20 July 2017 Accepted: 11 December 2017

Published online: 22 December 2017

\section{References}

1. Jeng MJ, Lee YS, Tsao PC, Soong WJ. Neonatal air leak syndrome and the role of high-frequency ventilation in its prevention. J Chin Med Assoc. 2012; 75:551-9.

2. Ratchada K, Rahman A, Pullenayegum EM, Sant'Anna GM. Positive airway pressure levels and pneumothorax: a case-control study in very low birth weight infants. J Matern Fetal Neonatal Med. 2011:24:912-6.

3. Migliori C, Campana A, Cattarelli D, Pontiggia F, Chirico G. Pneumothorax during nasal-CPAP: a predictable complication? Pediatr Med Chir. 2003;25: 345-8.

4. Kitsommart R, Martins B, Bottino MN, Sant'Anna GM. Expectant management of pneumothorax in preterm infants receiving assisted ventilation: report of 4 cases and review of the literature. Respir Care. 2012;57:789-93 
5. Litmanovitz I, Carlo WA. Expectant management of pneumothorax in ventilated neonates. Pediatrics. 2008;122:e975-9.

6. Giannantonio C, Sammartino M, Valente E, Cota F, Fioretti M, Papacci P. Remifentani analgosedation in preterm newborns during mechanical ventilation. Acta Paediatr. 2009;98(7):1111-5.

7. Gonzalez F, Harris T, Black P, Richardson P. Decreased gas flow through pneumothoraces in neonates receiving high-frequency jet versus conventional ventilation. J Pediatr. 1987;110:464-6.

8. Keszler M, Donn SM, Bucciarelli RL, Alverson DC, Hart M, Lunyong V, et al. Multicenter controlled trial comparing high-frequency jet ventilation and conventional mechanical ventilation in newborn infants with pulmonary interstitial emphysema. J Pediatr. 1991;119:85-93.

9. Frantz ID, Werthammer J, Stark AR. High-frequency ventilation in premature infants with lung disease: adequate gas exchange at low tracheal pressure. Pediatrics. 1983;71:483-8.

10. Keszler M, Abubakar MK. Physiologic principles. In: Goldsmith JP, Karotkin EH, editors. Assisted ventilation of the neonate. $5^{\text {th }}$ ed. St. Louis: Elsevier Saunders; 2011. p. 19-46.

11. Ellsbury DL, Klein JM, Segar JL. Optimization of high-frequency oscillatory ventilation for the treatment of experimental pneumothorax. Crit Care Med. 2002;30:1131.

12. Pillow J. Strategies for HFOV in various lung diseases. In: Drägerwerk AG, KGaA C, editors. High-frequency oscillatory ventilation: theory and practical applications. Allemagne: Lubeck; 2016. p. 51-4.

13. Ogata ES, Gregory GA, Kitterman JA, et al. Pneumothorax in the respiratory distress syndrome: incidence and effect on vital signs, blood gases and $\mathrm{pH}$. Pediatrics. 1976;58:177

\section{Submit your next manuscript to BioMed Central and we will help you at every step:}

- We accept pre-submission inquiries

- Our selector tool helps you to find the most relevant journal

- We provide round the clock customer support

- Convenient online submission

- Thorough peer review

- Inclusion in PubMed and all major indexing services

- Maximum visibility for your research

Submit your manuscript at www.biomedcentral.com/submit 